\title{
Macroalgal grazing by the green sea urchin: born to consume resources
}

\author{
Patrik Kraufvelin ${ }^{1}$
}

Received: 25 April 2017 / Accepted: 3 May 2017 / Published online: 15 May 2017

(C) Springer-Verlag Berlin Heidelberg 2017

Nos numerus sumus et fruges consumere nati.

[We are just statistics, born to consume resources].

-Horace

In their highlight article, Suskiewicz and Johnson (2017) review the scientific literature dealing with the control of feeding of the green sea urchin, Strongylocentrotus droebachiensis, and discuss the ecological implications of their findings. The phenomenon of sea urchins overgrazing marine temperate macroalgae (such as large kelp) leading to the transition of highly productive macroalgal forests into marine deserts in the form of barren urchin grounds (Fig. 1a-c) is well-known. In affected areas, urchins may persist for years after consuming the canopy algae, just by living on biofilms, drifting macroalgae and algal recruits, while maintaining the barren ground (Leinaas and Christie 1996). Without exaggeration, the macroalgal/urchin system constitutes a central corner-stone for the conceptual development of community ecology (e.g., Paine and Vadas 1969; Mann 1977; Paine 1980; Estes et al. 1998) and various aspects of the topic are frequently reported in this journal (some recent papers include, e.g., Fagerli et al. 2015; Nichols et al. 2015). However, to this very day, there are still apparent gaps in our knowledge regarding many of the processes and mechanisms involved in defining the two alternative stable states of these ecosystems (Filbee-Dexter and Scheibling 2014; Ling et al. 2015). By scrutinizing existing

Responsible Editor: U. Sommer.

Patrik Kraufvelin

patrik.kraufvelin@slu.se

1 Department of Aquatic Resources, Institute of Coastal Research, Swedish University of Agricultural Sciences, Skolgatan 6, 74242 Öregrund, Sweden information of consumption rates and factors controlling the feeding of a common and widely distributed sea urchin species at higher latitudes in the northern hemisphere, the green sea urchin, Suskiewicz and Johnson (2017) deliver a vital synthesis for improved understanding of this specific phenomenon, its dynamics and mechanisms, as well as its ecological consequences.

The main results from the literature review by Suskiewicz and Johnson (2017) concern factors that under laboratory conditions have been reported to control sea urchin consumption rates such as urchin size, urchin reproductive state, water temperature and algal species (food type). Although bigger urchin individuals as expected ate more than smaller individuals, the small ones consumed food at the same rates as the big ones, suggesting that simple estimations of total urchin biomass may be sufficient for the evaluation of the potential herbivore pressure in an area. A more surprising finding was that temperature did not have any clear impact on feeding rates presenting quite ambiguous results when viewed in the larger picture. The consumption of different types of macroalgae and of the same algal species during different occasions and in different regions was also puzzling at times. All algal taxa offered to the urchins were eaten and even though some species clearly were preferred above others, the actual favoured ones often differed among regions and typically ignored species could at certain places be eaten at high rates.

Among the central take home messages from this review, the estimates of the maximum amounts of algae that an urchin can consume stand out explicitly as these values are quantifying key elements of the macroalgal/urchin dynamics. If consumption rates together with changes in urchin abundance are coupled with macroalgal productivity estimates of a location, ecological tipping points in the transition from macroalgal forests to barren grounds may 

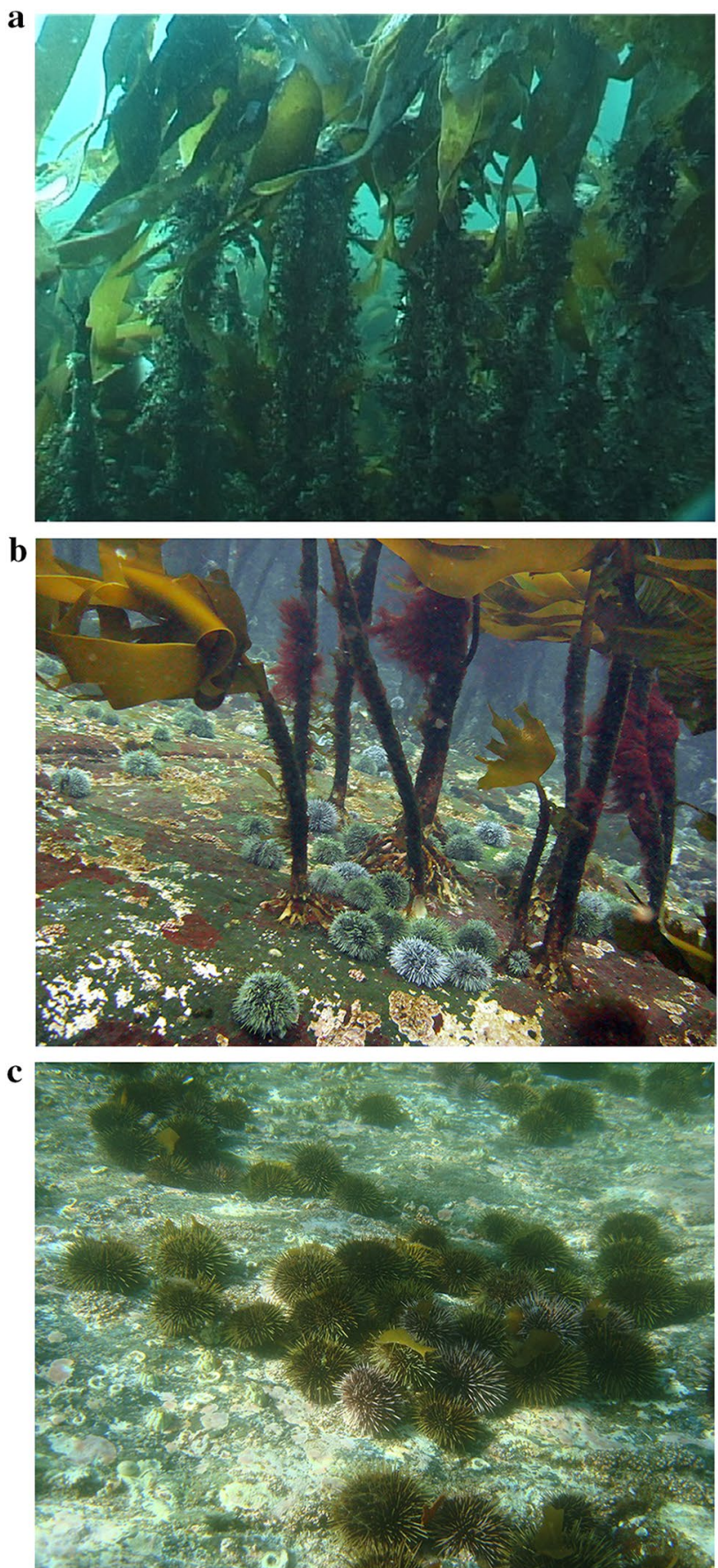

Fig. 1 Visual representation of the macroalgal/urchin transition from one stable state to another in Norway: a Laminaria hyperborea forest; b L. hyperborea co-existing with the green sea urchin; Strongylocentrotus droebachiensis; $\mathbf{c}$ urchin barren ground. Photos: H. Christie

more easily be singled out. In order to succeed in these "higher" goals, however, the examined laboratory-based studies and their inherent information need to be scaled up to the whole-ecosystem context, as also the authors meritoriously point out (Suskiewicz and Johnson 2017). This could be done by well-designed experiments in controlled mesocosms or in the field under natural background levels of environmental variables and natural species compositions of macroalgal assemblages coupled with realistic levels of naturally behaving sea urchins, competing herbivores and predators. By experimental manipulation of one or more of these trophic levels or specific factors, alone or in combination, more answers to the old ecological problem of transitions between macroalgal forests and barren grounds can be obtained. The balance between the rates of macroalgal primary production and herbivore consumption is in this respect crucial for determining the resilience of the macroalgal habitat to grazing and also of its recovery potential, once it has been subjected to overconsumption of its standing biomass resources by sea urchins, organisms seemingly born to (over)consume resources.

\section{Compliance with ethical standards}

Conflict of interest There is no conflict of interest of any kind.

Research involving human participants and/or animals No research involving human participants and/or animals has been conducted for this editorial comment.

Informed consent Informed consent has been obtained from all individual participants included in the study (the authors of the highlight article and the photographer of the pictures in Fig. 1).

\section{References}

Estes JA, Tinker MT, Williams TM, Doak DF (1998) Killer whale predation on sea otters linking oceanic and nearshore ecosystems. Science 282:473-476

Fagerli CW, Stadniczeñko SG, Pedersen MF, Christie H, Fredriksen S, Norderhaug KM (2015) Population dynamics of Strongylocentrotus droebachiensis in kelp forests and barren grounds in Norway. Mar Biol 162:1215-1226

Filbee-Dexter K, Scheibling RE (2014) Sea urchin barrens as alternative stable states of collapsed kelp ecosystems. Mar Ecol Prog Ser 495:1-25

Leinaas HP, Christie HC (1996) Effects of removing sea urchins (Strongylocentrotus droebachiensis): stability of the barren state and succession of kelp forest recovery in the east Atlantic. Oecologia 105:524-536

Ling SD, Scheibling RE, Johnson CR, Rassweiler R, Shears N, Connell SD, Salomon AK, Norderhaug KM, Perez-Matus A, Hernandez JC, Clemente S, Blamey LK, Hereu B, Ballesteros E, Sala E, Garrabou J, Cebrian E, Zabala M, Fujita D, Johnson LE (2015) Global regime-shift dynamics of catastrophic sea urchin overgrazing. Philos T Roy Soc B 370:20130269

Mann KH (1977) Destruction of kelp-beds by sea urchins: a cyclical phenomenon or irreversible degradation? Helgoland Wiss Meer 30:455-467

Nichols KD, Segui L, Hovel KA (2015) Effects of predators on sea urchin density and habitat use in a southern California kelp forest. Mar Biol 16:1227-1237 
Paine RT (1980) Food webs: linkage, interaction strength and community infrastructure. J Anim Ecol 49:667-685

Paine RT, Vadas RL (1969) The effects of grazing by sea urchins, Strongylocentrotus spp., on benthic algal populations. Limnol Oceanogr 14:710-719
Suskiewicz TS, Johnson LE (2017) Consumption rates of a key marine herbivore: a review of the extrinsic and intrinsic control of feeding in the green sea urchin. Mar Biol. doi:10.1007/ s00227-017-3159-0 